\title{
A NEW SPECIES OF COPEPOD FROM THE EDDYSTONE SHELL GRAVEL
}

\author{
BY S. KRISHNASWAMY \\ Department of Zoology, University of Southampton
}

(Text-figs. I-2)

Recent investigations of the bottom fauna off Plymouth by Spooner $(1959 a, b)$ have revealed the existence of a number of unusual and interesting crustaceans. The copepods collected during this investigation were very kindly placed at the disposal of the writer for study. A careful examination of the collection revealed the presence of a second and new species of Paramisophria Scott. This genus was established in 1897 by Scott on the basis of females collected in Scotland. Sars (1903) described the male for the first time. Paramisophria cluthae, the only species known previously, has been recorded from Plymouth.

\section{Paramisophria spooneri nov.sp.}

\section{The Female (Fig. I A-L)}

Body cyclopoid in shape and slightly compressed laterally. The anterior end of the cephalosome is rounded while the posterior margin is slightly produced and bears a small tooth about its middle (Fig. IB). The urosome is short and is about a third of the total length. Caudal rami (Fig. ID) are wider than long and each ramus bears six setae. Its inner margin is hirsute.

The antennule is short and only 20 segments could be made out clearly (Fig. IC). It carries a number of aesthetes. The basal segment is nearly $4 \frac{1}{2}$ times longer than the succeeding joint. The antenna is biramous, both the rami being two-jointed (Fig. IF). The endopod is short and the terminal joint which is short carries one apical and two lateral setae. The exopod is long and slender, its terminal joint being slightly shorter than the basal joint, carrying two lateral and four apical setae. Thus the antenna differs from that of Paramisophria cluthae Scott, where the endopod is 6-jointed and also carries a larger number of setae. Other oral appendages are as in $P$. cluthae. The maxillule however differs in that it shows a reduction in the number of setae it carries (Fig. I G).

The rami of the first four pairs of the swimming feet are 3-segmented. The first pair (Fig. $\mathrm{IH}_{\mathrm{H}}$ ) is slightly shorter than the other pairs. Basal ${ }_{2}$ has an outer seta. The first and the second joints of the exopod carry an outer spine and an inner seta each and the terminal joint one apical and two outer spines and four inner setae. The endopod is nearly as long as the exopod and the outer distal corner of the second and the third joints is produced into a spinous projection. The first joint carries an inner seta, the second joint two inner setae and the terminal joint a short plumose outer spine and four inner setae. The seta formulae of the second, third and fourth legs are shown in Table $\mathrm{I}$. 


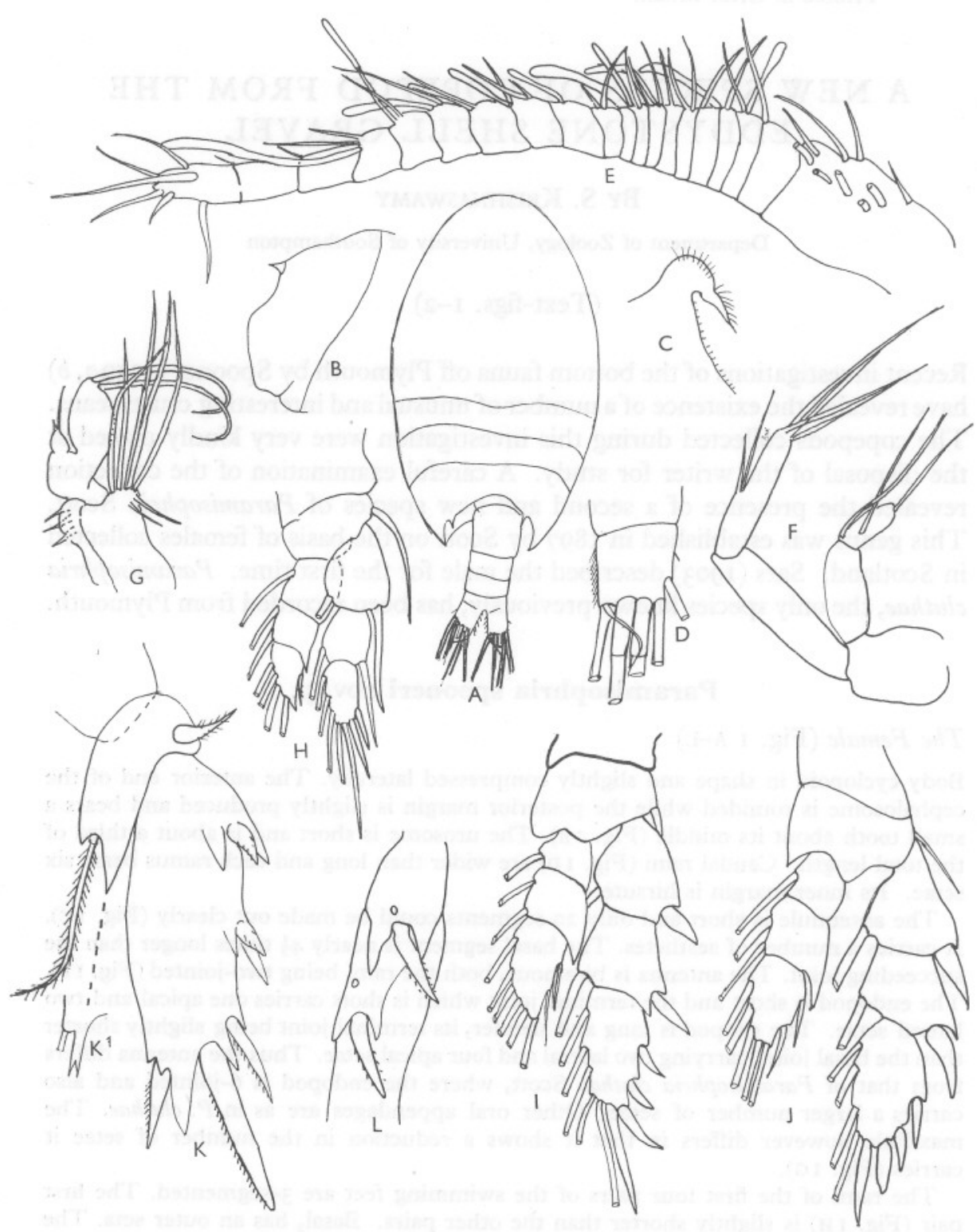

Fig. I. Paramisophria spooneri n. sp. Female. A, dorsal view; B, posterior margin of metasome, lateral view; C, labrum, lateral view; $\mathrm{D}$, caudal ramus; $\mathrm{E}$, antennule; $\mathrm{F}$, antenna; $\mathrm{G}$, maxillule; $\mathrm{H}, \mathrm{I}$, J, swimming feet $\mathrm{I}, 2$ and $3 ; \mathrm{K}$, fifth leg; $\mathrm{K}^{1}$, end of the inner projection with the bifid end; $\mathbf{L}$, lateral view of the fifth leg showing the insertion of spines. 
Fifth leg (Fig. I K) consists of a small basal joint and a long and slender distal joint. The basal joint has an inner as well as an outer seta and is produced on the inner side into a process with a bifid end. The distal joint, which is three times longer than wide, is produced into a spinous process terminally. It carries an outer apical and three outer lateral spines. The outer lateral spines are borne on processes which are produced on either side, as may be clearly seen in a lateral view (Fig. IL). In P. cluthae on the other hand, the inner margin of the basal joint is not produced into a bifid process. Length: $0.62 \mathrm{~mm}$.

TABLE 1

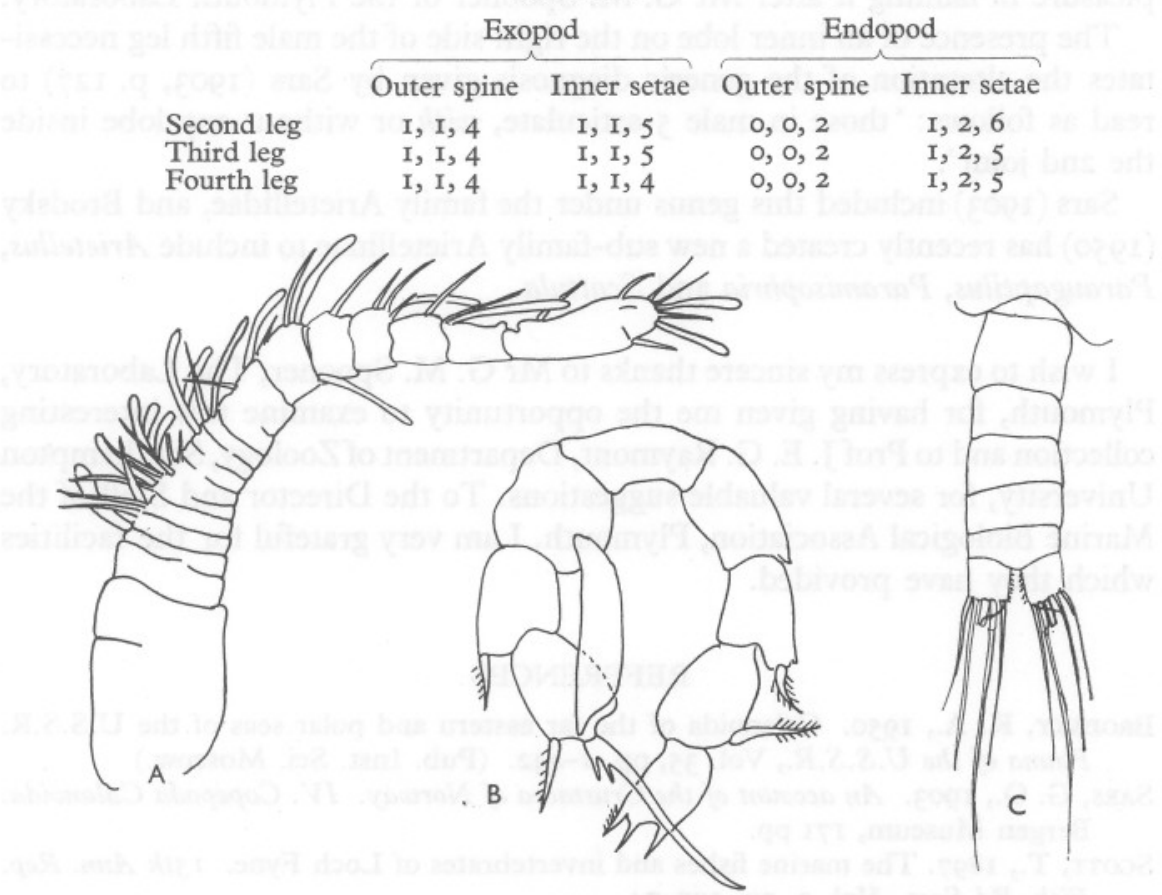

Fig. 2. Paramisophria spooneri n.sp. Male. A, antennule; B, fifth leg; c, urosome.

\section{The Male}

Resembles the female in general shape of the body. The urosome is however 5-jointed (Fig. 2C). The antennule is r9-jointed and is geniculate on the left side, having the last segment feebly and imperfectly hinged to the penultimate segment (Fig. 2A). The antenna and oral appendages as well as the first four pairs of swimming feet are as in the female. The fifth pair is modified and is 5-jointed (Fig. 2B). On the left the third and the fourth joints carry an outer plumose spine each while the terminal joint which is spatulate is produced into three processes which are spinous, thus giving the appearance of a three-pronged process to the joint. On the right side, the second joint carries a blunt process which is long and reaches up to the end of the fourth joint. The third and the fourth joints carry an outer plumose spine each. The terminal joint is a long slender process with two teeth at its base on the outer side. Length: $0.62 \mathrm{~mm}$. 


\section{Remarks}

The present species resembles Paramisophria cluthae Scott very closely. It differs from it, however, in the structure of the antenna and fifth legs. The presence of a long unarmed blunt process on the second joint on the right side of the male fifth leg is a feature unique for this species. In view of these differences the present species is treated as a new one. I have great pleasure in naming it after Mr G. M. Spooner of the Plymouth Laboratory.

The presence of an inner lobe on the right side of the male fifth leg necessitates the alteration of the generic diagnosis given by Sars (1903, p. 127) to read as follows: 'those in male 5-articulate, with or without any lobe inside the 2nd joint'.

Sars (1903) included this genus under the family Arietellidae, and Brodsky (I950) has recently created a new sub-family Arietellinae to include Arietellus, Paraugaptilus, Paramisophria and Scottula.

I wish to express my sincere thanks to Mr G. M. Spooner, The Laboratory, Plymouth, for having given me the opportunity to examine this interesting collection and to Prof J. E. G. Raymont, Department of Zoology, Southampton University, for several valuable suggestions. To the Director and Staff of the Marine Biological Association, Plymouth, I am very grateful for the facilities which they have provided.

\section{REFERENCES}

BRodsky, K. A., r950. Calanoida of the far eastern and polar seas of the U.S.S.R. Fauna of the U.S.S.R., Vol. 35, pp. I-442. (Pub. Inst. Sci. Moscow.)

SARS, G. O., I903. An account of the Crustacea of Norway. IV. Copepoda Calanoida. Bergen Museum, I7I pp.

Scotт, T., 1897. The marine fishes and invertebrates of Loch Fyne. 15th Ann. Rep. Fish. Bd Scot., Vol. 3, pp. 107-74.

SPOONER, G. M., I959a. The occurrence of Microcharon in the Plymouth offshore bottom fauna, with description of a new species. F. mar. biol. Ass. U.K., Vol. 38, pp. $57-63$.

- 1959b. New members of the British marine bottom fauna. Nature, Lond., Vol. I83, pp. 1695-6. 